\title{
Chapter 3 \\ A New Aspect of Cholinergic Transmission in the Central Nervous System
}

\author{
Ikunobu Muramatsu, Takayoshi Masuoka, Junsuke Uwada, Hatsumi Yoshiki, \\ Takashi Yazama, Kung-Shing Lee, Kiyonao Sada, Matomo Nishio, \\ Takaharu Ishibashi, and Takanobu Taniguchi
}

\begin{abstract}
In the central nervous system, acetylcholine (ACh) is an important neurotransmitter related to higher brain functions and some neurodegenerative diseases. It is released from cholinergic nerve terminals and acts on presynaptic and postsynaptic ACh receptors (AChRs). Following release, $\mathrm{ACh}$ is rapidly hydrolyzed and the resultant choline is recycled as a substrate for new ACh synthesis. However, this classical concept of cholinergic transmission is currently reevaluated due to new evidence. In the cholinergic synapse, ACh may be itself taken up into postsynaptic neurons by a specific transport system and may act on AChRs at intracellular organelles (Golgi apparatus and mitochondria). Choline for ACh synthesis in cholinergic nerve terminals may be mainly supplied from choline at relevant concentration levels
\end{abstract}

\footnotetext{
I. Muramatsu $(\bowtie)$

Department of Pharmacology, School of Medicine, Kanazawa Medical University, Uchinada, Ishikawa, Japan

Division of Genomic Science and Microbiology, School of Medicine,

University of Fukui, Eiheiji, Fukui, Japan

Kimura Hospital, Awara, Fukui, Japan

e-mail: muramatu@u-fukui.ac.jp

T. Masuoka $\cdot$ M. Nishio $\cdot$ T. Ishibashi

Department of Pharmacology, School of Medicine, Kanazawa Medical University,

Uchinada, Ishikawa, Japan

J. Uwada $\cdot$ T. Yazama $\cdot$ T. Taniguchi

Division of Cellular Signal Transduction, Department of Biochemistry,

Asahikawa Medical University, Asahikawa, Hokkaido, Japan

H. Yoshiki · K. Sada

Division of Genomic Science and Microbiology, School of Medicine,

University of Fukui, Eiheiji, Fukui, Japan

K.-S. Lee

Division of Genomic Science and Microbiology, School of Medicine,

University of Fukui, Eiheiji, Fukui, Japan

Department of Surgery, Kaohsiung Medical University, Kaohsiung, Taiwan
} 
present in the extracellular space, rather than recycled from ACh-derived choline. Recent evidence has reopened the issue of classical cholinergic transmission and cognition, and may provide a novel approach to rational drug development for the treatment of neurodegenerative disorders such as Alzheimer's disease.

Keywords Cholinergic transmission · Intracellular acetylcholine receptors · Acetylcholine uptake $\cdot$ Acetylcholine esterase $\cdot$ Presynaptic muscarinic receptors

\section{Abbreviations}

$\begin{array}{ll}\text { ACh } & \text { Acetylcholine } \\ \text { AChE } & \text { Acetylcholine esterase } \\ \text { AChR } & \text { Acetylcholine receptor } \\ \text { AChT } & \text { Acetylcholine transporter } \\ \mathrm{Ca}^{2+} & \text { Calcium } \\ \text { CHT1 } & \text { High affinity-choline transporter 1 } \\ \text { CNS } & \text { Central nervous system } \\ \text { DFP } & \text { Diisopropylfluorophosphate } \\ \text { ERK } & \text { Extracellular regulated kinase } \\ \text { HC-3 } & \text { Hemicholinium-3 } \\ \text { LTP } & \text { Long term-potentiation } \\ \text { mAChR } & \text { Muscarinic acetylcholine receptor } \\ \text { MAPK } & \text { Mitogen-activated protein kinase } \\ \text { nAChR } & \text { Nicotinic acetylcholine receptor } \\ \text { NMDAR } & N \text {-methyl-D-aspartate receptor } \\ \text { NMS } & \text { N-methyl-scopolamine } \\ \text { PIP } & \text { Phosphatidylinositol 4,5-bisphosphate } \\ \text { QNB } & \text { Quinuclidinyl benzilate } \\ \text { TEA } & \text { Tetraethylammonium }\end{array}$

\subsection{Introduction}

In the central nervous system (CNS), acetylcholine (ACh) is one of the major neurotransmitters involved in higher brain functions, including cognitive processes such as learning and memory and extrapyramidal locomotor activity (Everitt and Robbins 1997; Terry and Buccafusco 2003; Mesulam 2004; Wess et al. 2007). In cholinergic transmission, released ACh acts on ACh receptors (AChRs) located on the presynaptic and/or postsynaptic plasma membranes. ACh is also rapidly hydrolyzed by ACh esterase (AChE), leading to the termination of synaptic neurotransmission. Then the resultant choline is transported back into the cholinergic nerve 
terminals by the high-affinity choline transporter 1 (CHT1), and is reutilized as a substrate for ACh synthesis (Parsons et al. 1993; Apparsundaram et al. 2000; Okuda et al. 2000; Sarter and Parikh 2005). However, this classical tenet of cholinergic transmission has recently been challenged by several new findings from recent studies. The first finding is with regard to the intracellular distribution and function of AChRs in postsynaptic neurons and neuroblastoma cells (Yamasaki et al. 2010: Uwada et al. 2011, 2014; Anisuzzaman et al. 2013; Muramatsu et al. 2015); the second is the incorporation of $\mathrm{ACh}$ itself into postsynaptic neurons (Muramatsu et al. 2016); and the third finding is that ACh-derived choline after hydrolysis may not be largely reused (Muramatsu et al. 2017). In this chapter, these findings were briefly summarized.

\subsection{Intracellular Distribution of AChRs}

It has been commonly accepted that most neurotransmitter receptors are located on the plasma membrane and transduce extracellular to intracellular signals. However, recent evidence suggests that several G-protein-coupled receptors including AChRs are located, and may also signal from, intracellular sites such as endosomes, Golgi apparatus, endoplasmic reticulum, mitochondria, and nuclear membranes (Boivin et al. 2008; Jong et al. 2009; Benard et al. 2012; den Boon et al. 2012; Uwada et al. 2011, 2014; Anisuzzaman et al. 2013).

\subsubsection{Muscarinic AChRs}

There are five subtypes of muscarinic AChRs (M1-M5 mAChRs), all of which are expressed in the CNS (Caulfield and Birdsall 1998; van Koppen and Kaiser 2003; Nathanson 2008). In general, the M1 subtype is the most abundant within the CNS, M2 and M4 subtypes are moderately expressed, and only low levels of M3 and M5 subtypes have been found (Volpicelli and Levery 2004). All of the mAChRs are generally located and function at the plasma membrane. However, recent studies have revealed that M1 mAChRs exist not only at the cell surface but also at intracellular membranes in the hippocampus and other telencephalon regions of rodents and humans and in neuroblastoma cells (Uwada et al. 2011; Anisuzzaman et al. 2013). Pharmacologically, the intracellular distribution of mAChRs is evaluated from the different binding densities of cell-permeable (hydrophobic) and cellimpermeable (hydrophilic) radioligands, $\left[{ }^{3} \mathrm{H}\right]$ quinuclidinyl benzilate (QNB) and $\left[{ }^{3} \mathrm{H}\right] \mathrm{N}$-methyl-scopolamine (NMS), respectively, in intact segments of brain tissue or whole neuronal cells to detect total (QNB binding) and cell surface (NMS binding) mAChRs (Muramatsu et al. 2005, 2015), and proportions of intracellular and surface M1 subtypes are estimated from the competing profiles of M1-selective 
ligands at the binding sites of both radioligands. Comparable amounts of surface and intracellular M1 mAChRs were identified under conditions where brain tissues or cultured neurons were not stimulated beforehand. Therefore, it is likely that approximately half the amount of M1 mAChR constitutively occurs at intracellular sites in the telencephalon and in neuroblastoma cells. Intracellular M1 mAChRs were immunohistochemically shown to localize at the Golgi apparatus, and a recent molecular biology study revealed that their intracellular localization requires the C-terminal tryptophan-based motif of M1 subtype, which does not exist in other subtypes (Uwada et al. 2014; Anisuzzaman et al. 2013). The abundant distribution of M1 mAChRs in the Golgi apparatus and endoplasmic reticulum of pyramidal neurons but not in astroglia was also demonstrated in immunoelectron microscopic studies (Yamasaki et al. 2010). A previous immunohistochemical study with a specific M1 antibody also reported intracellular detection in the cytoplasm of large and small dendrites and the dendritic spines of cerebral cortex neurons (Mrzljak et al. 1993).

M1 mAChRs cause phosphatidylinositol 4,5-bisphosphate $\left(\mathrm{PIP}_{2}\right)$ hydrolysis leading to calcium $\left(\mathrm{Ca}^{2+}\right)$ upregulation and activation of the mitogen-activated protein kinase (MAPK) pathway through the $\mathrm{G} \alpha_{q^{\prime 11}}$ protein (van Koppen and Kaiser 2003; Morishima et al. 2013). In rat hippocampal and cortical neurons and neuroblastoma cells, the $\mathrm{PIP}_{2}-\mathrm{Ca}^{2+}$ response is exclusively mediated by surface M1 $\mathrm{mAChRs}$ on a time scale of seconds. On the other hand, the extracellular signalregulated kinase1/2 (ERK1/2) pathway is activated by intracellular M1 mAChRs on a slow time scale of minutes (Uwada et al. 2011; Anisuzzaman et al. 2013). These results indicate that M1 mAChRs at each site may be specifically activated and involved in distinct neuronal functions with different temporal courses (Fig. 3.1).

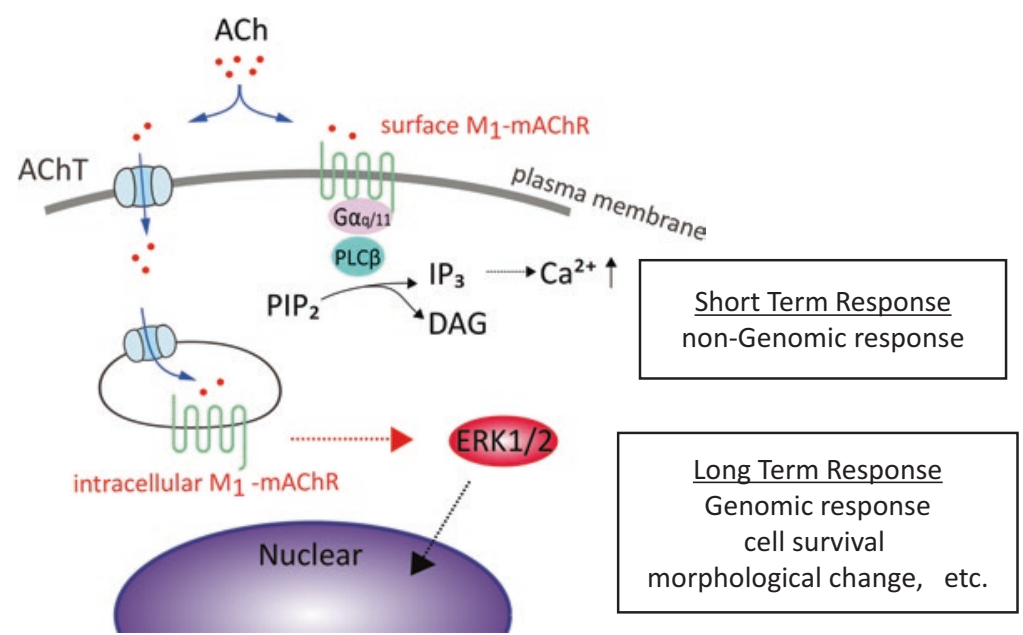

Fig. 3.1 Schematic representation of surface and intracellular M1 mAChRs in postsynaptic neurons, and their possible signal transduction pathways and physiological responses 
As aforementioned, M1 mAChRs predominantly exist in the CNS and are involved in cognitive enhancement (Everitt and Robbins 1997; Kruse et al. 2014; Terry and Buccafusco 2003; Mesulam 2004; Wess et al. 2007). In the hippocampus, cholinergic activation induces a theta rhythm of neuronal activity and enhances or induces long-term potentiation (LTP) (Huerta and Lisman 1995; Williams and Kauer 1997; Fernandez de Sevilla et al. 2008), the primary experimental model for investigating the synaptic basis of learning and memory (Bliss and Collingridge 1993; Seol et al. 2007). M1 mAChR-knockout mice have severe deficits in working memory and memory consolidation, as well as impaired hippocampal LTP (Anagnostaras et al. 2003; Shinoe et al. 2005; Wess et al. 2007). M1-specific agonists have been shown to facilitate the induction of LTP and improve cognitive function in several animal models of amnesia (Caccamo et al. 2006; Langmead et al. 2008; Ma et al. 2009). Thus, the specific distribution of intracellular M1 mAChRs in the telencephalon may correlate with synaptic plasticity.

Our electrophysiological study with rat hippocampal slices revealed that cholinergic induction of a theta rhythm and cholinergic facilitation in the early part of $\mathrm{N}$-methyl-d-aspartate receptor (NMDAR)-dependent LTP were mainly mediated by surface M1 mAChRs, whereas cholinergic facilitation in the late part of NMDARdependent LTP and the majority of non-NMDAR-dependent LTP were evoked by activation of intracellular M1 mAChRs (Anisuzzaman et al. 2013). The induction of LTP requires elevation of postsynaptic $\mathrm{Ca}^{2+}$ (Lynch et al. 1983) and activation of protein kinases (Soderling and Derkack 2000), whereas the maintenance of latephase LTP depends on the MAPK/ERK cascade, gene transcription, protein synthesis, and posttranslational modification (Davi et al. 2000; Giovannini 2006; Nguyen et al. 1994; Frey et al. 1996; Bliss and Collingridge 1993; Routtenberg and Rekart 2005; Gold 2008). Taking these mechanisms into consideration, it is likely that cholinergic stimulation may primarily cause the selective enhancement of respective signaling processes in the early and late phases of LTP through M1 mAChRs located at two distinct sites, leading cholinergic facilitation (Fig. 3.2).

\subsubsection{Nicotinic AChRs}

The nicotinic AChRs (nAChRs) are widely expressed in the brain, where they maintain various neuronal functions including learning and memory (Terry and Buccafusco 2003; Dineley et al. 2015; Wu et al. 2016). They also control survival/ death, proliferation/neurite outgrowth, and neurotransmitter release in neuronal cells (Akaike et al. 1994; Kihara et al. 2001; Shimohama et al. 1996; 2009; Rosa et al. 2006). The major nAChR subtypes in the CNS are heteromeric $\alpha 4 \beta 2, \alpha 3 \beta 2$, $\alpha 7 \beta 2$ and homomeric $\alpha 7$ assemblies, all of which have high permeability for $\mathrm{Ca}^{2+}$ as ionic channels and also transduce signals through the phosphatidylinositol 3-kinase (PI3K) signaling pathway (Kihara et al. 2001; Dajas-Bailador and Wonnacott 2004; also see other chapters in this book). To date, these responses have been mainly 


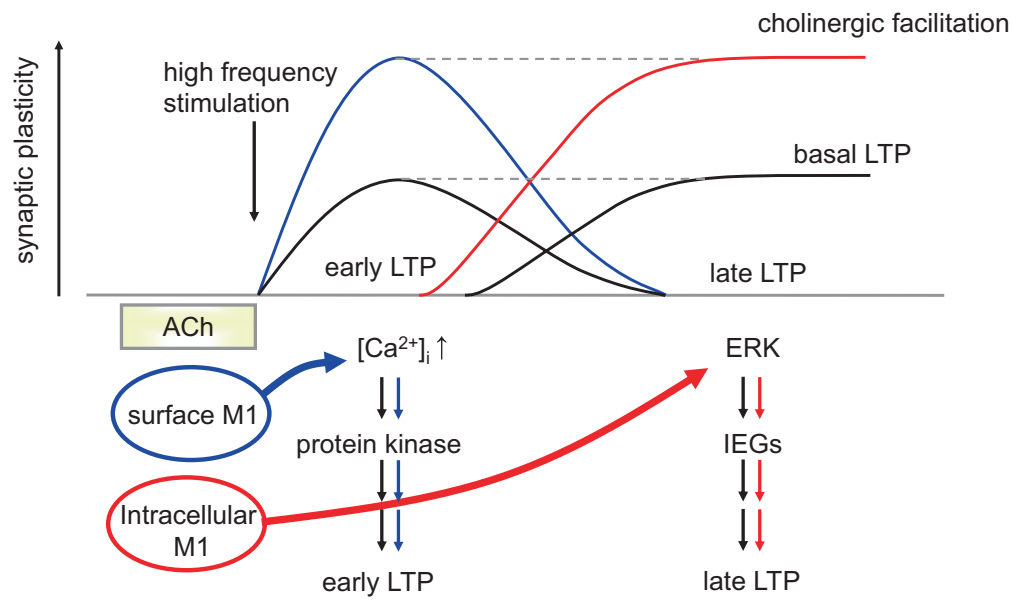

Fig. 3.2 Involvement of surface and intracellular M1 mAChRs in cholinergic facilitation of LTP in rat hippocampus. Note that early and late stages of basal LTP are represented to be primarily mediated by two distinct signal pathways, which are independently enhanced by surface and intracellular M1 mAChRs. Blue: surface M1 mAChR-mediated. Red: intracellular M1 mAChRmediated. IEGs immediately early genes

discussed with special reference to nAChRs located on the plasma membrane; however, the intracellular distribution of nAChRs, especially in the mitochondria, was recently reported in immunochemical studies (Lykhmus et al. 2014; Gergalova et al. 2014). In brain mitochondria, $\alpha 7 \beta 2 \mathrm{nAChRs}$ mainly stimulate the PI3K/AKT pathway, and $\alpha 3 \beta 2$ and $\alpha 4 \beta 2$ nAChRs inhibit Src- and $\mathrm{Ca}^{2+} /$ calmodulin-dependent protein-kinase II pathways. Mitochondrial nAChRs and associated signaling pathways are associated with the induction of mitochondrial apoptosis (Lykhmus et al. 2014). However, more detailed analysis from different approaches is required in this issue.

\subsection{Incorporation of ACh into Postsynaptic Neurons}

To activate intracellular AChRs, the endogenous agonist ACh must cross the postsynaptic plasma and endosomal membranes. Because ACh is a hydrophilic molecule, the presence of a specific ACh transport system such as the ACh transporter (AChT) has been postulated (Muramatsu et al. 2016) (Fig. 3.1). Although detailed information on the AChT is lacking, incorporation of ACh into brain slices was reported more than four decades ago (Polak and Meeuws 1996; Liang and Quastel 1969; Katz et al. 1973; Kuhar and Simon 1974). More recently, previous evidence showing that $\left[{ }^{3} \mathrm{H}\right] \mathrm{ACh}$ is actively taken up into brain segments in time- and 
temperature-dependent manners was confirmed (Muramatsu et al. 2016, 2017). The uptake was clearly observed in the presence of irreversible but not reversible AChE inhibitors. $\left[{ }^{3} \mathrm{H}\right] \mathrm{ACh}$ uptake was high in the CNS but was negligible or minor in the peripheral tissues. The uptake was comparable among brain regions but was not related to the density of cholinergic innervation. Hemicholinium-3 (HC-3) and tetraethyammonium (TEA) inhibited $\left[{ }^{3} \mathrm{H}\right] \mathrm{ACh}$ uptake in a concentration-dependent manner. However, the uptake was little affected by the excitatory or inhibitory amino acid neurotransmitters glutamate and gamma-aminobutyric acid, respectively, biogenic amines, tetrodotoxin, and atropine. Therefore, it is likely that $\mathrm{ACh}$ uptake is facilitated by an intrinsic transport system $(\mathrm{AChT})$, rather than a change in neuronal excitability and the involvement of amino acid neurotransmitters. Interestingly, $\left[{ }^{3} \mathrm{H}\right] \mathrm{ACh}$ uptake was potently suppressed by $\mathrm{AChE}$ inhibitors including drugs clinically used to treat the cognitive symptoms of Alzheimer's disease such as donepezil, galantamine and rivastigmine (Muramatsu et al. 2016). These results raise the interesting possibility that $\mathrm{ACh}$ concentrations released in the synapse may be regulated by both $\mathrm{AChE}$ and the postsynaptic uptake of $\mathrm{ACh}$, which may be relevant to cholinergic therapy in Alzheimer's disease. As mentioned above, intracellular M1 mAChRs selectively activate ERK in hippocampal neurons and participate in the late stage of cholinergic facilitation of LTP. The intracellular M1-mediated responses both were inhibited by TEA and HC-3 at concentrations that inhibit ACh uptake. However, PIP $_{2}$ hydrolysis and the early phase of cholinergic facilitation of LTP, which were selectively caused by plasma membrane M1 AChRs, were not affected by TEA and HC-3 (Uwada and Masuoka unpublished observations). These pharmacological results further support the fact that cholinergic facilitation of LTP is caused independently by surface and intracellular M1 mAChRs through distinct signaling pathways (Figs. 3.1 and 3.2). These results also indicate that the ACh transport system serves as an intrinsic route for released $\mathrm{ACh}$ to access intracellular AChRs in postsynaptic neurons.

\subsection{Regulation of Synaptic ACh Concentrations and the Choline-ACh Cycle}

In the $\mathrm{CNS}$, release of $\mathrm{ACh}$ from the cholinergic nerve terminals is negatively regulated through presynaptic mAChRs (Raiteri et al. 1989; Starke et al. 1989; Zhang et al. 2002; Alquicer et al. 2016). In vitro, this release is monitored with the superfusion technique, where ACh in synaptosomes (Raiteri and Raiteri 2000; Pittaluga 2016) and brain slices (Richardson and Szerb 1974; Zhang et al. 2002; Alquicer et al. 2016) has been synthesized/prelabeled in advance with $\left[{ }^{3} \mathrm{H}\right]$ choline followed by superfusion. Figure 3.3a shows a representative result obtained from a superfusion experiment with rat striatal slices. Atropine dramatically increased $\left[{ }^{3} \mathrm{H}\right] \mathrm{efflux}$ evoked by electrical stimulation, indicating that blockade of presynaptic mAChRs suppressed autoinhibition of ACh release. Although the presynaptic mAChR 
A

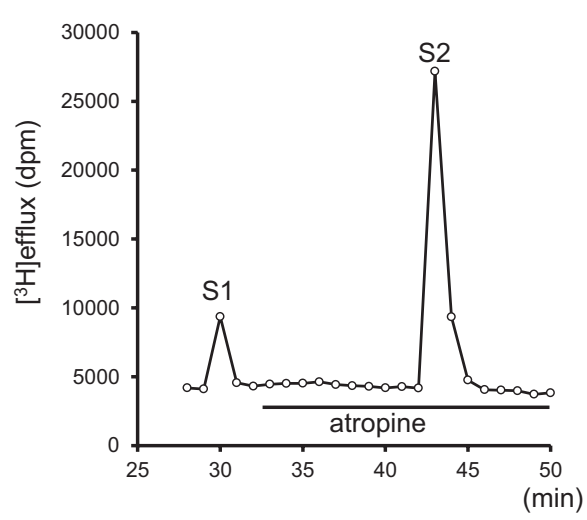

B

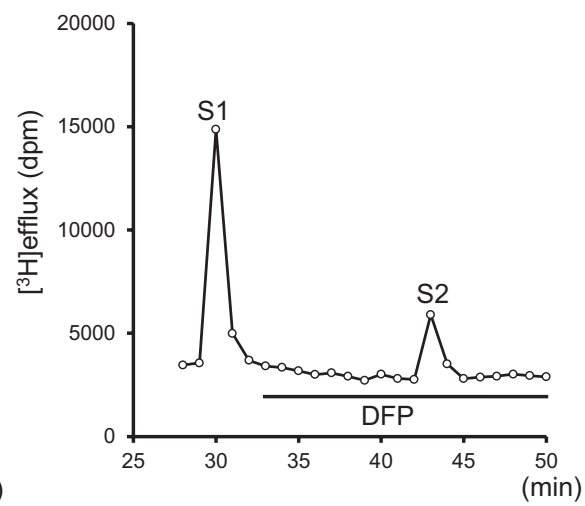

Fig. 3.3 Effects of atropine and diisopropyl phosphorofluoridate in $\left[{ }^{3} \mathrm{H}\right]$ efflux in superfusion experiments. Rat striatal segments were incubated with $0.1 \mu \mathrm{M}\left[{ }^{3} \mathrm{H}\right]$ choline for $30 \mathrm{~min}$ and then superfused. Electrical stimulation ( $3 \mathrm{~Hz}$, for $30 \mathrm{~s}$ ) was applied two times (S1 and S2). (a) $0.1 \mu \mathrm{M}$ atropine. (b) $300 \mu \mathrm{M}$ diisopropyl phosphorofluoridate (DFP). Ordinate: $\left[{ }^{3} \mathrm{H}\right]$ count (dpm) in superfusate collected every minute. Abscissa: time after superfusion

subtypes that participate in autoregulation have been the subject of debate, it was recently concluded that the $\mathrm{M} 2$ subtype has dominant involvement and there is only minor participation of the M4 subtype (Dolezal and Tucek 1998; Fadel 2011; Zhang et al. 2002; Alquicer et al. 2016).

Released ACh is rapidly hydrolyzed by AChE. Compared with the peripheral tissues, AChE activity in the brain (except cerebellum) is extremely high, and esterase activity in the CNS is closely related to the density of cholinergic innervation (Muramatsu et al. 2016). The esterase activity in the rat striatum is more than five times higher than that in the cerebral cortex and hippocampus, whereas the lowest activity is in the cerebellum, on par with that of the heart and colon. Thus, concentrations of released ACh appear to be effectively regulated by AChE in the CNS.

Inhibition of AChE would be thought to elicit a dramatic increase in synaptic ACh concentration; however, the scenario is not so simple. As mentioned above, $\mathrm{ACh}$ release is negatively regulated by presynaptic autoreceptors. Thus, it is likely that $\mathrm{AChE}$ inhibitors suppress hydrolysis of released $\mathrm{ACh}$, which in turn, enhances stimulation of presynaptic $\mathrm{mAChRs}$. Figure $3.3 \mathrm{~b}$ shows a representative result in rat striatal slices, where $\left[{ }^{3} \mathrm{H}\right]$ efflux evoked by electrical stimulation $(3 \mathrm{~Hz}, 30 \mathrm{~s})$ was reduced after treatment with an irreversible AChE inhibitor (diisopropyl fluorophosphate [DFP]). This inhibitory effect of DFP was abolished by atropine (Muramatsu unpublished observations). These results strongly suggest that ACh release and synaptic concentrations of ACh are precisely controlled by the subtle balance between AChE activity and presynaptic autoinhibition. 
In addition to presynaptic $\mathrm{AChRs}$ and $\mathrm{AChE}$, the postsynaptic uptake of $\mathrm{ACh}$ itself also regulates synaptic ACh concentrations (Muramatsu et al. 2017). In Sect. 3.3, it was noted that ACh uptake is inhibited by TEA and HC-3. The concentration of both drugs that suppressed ACh uptake significantly increased the evoked $\left[{ }^{3} \mathrm{H}\right]$ efflux by electrical stimulation in superfusion experiments. The effects of TEA or HC-3 were not related to inhibitory actions on presynaptic mAChRs or AChE activity, because the effects of both drugs were observed under conditions which $\mathrm{mAChRs}$ and AChE were completely inhibited. Therefore, it is possible that a portion of released ACh may be incorporated into postsynaptic neurons by AChT, participating in the regulation of synaptic ACh concentrations.

After hydrolysis by AChE, it has been classically proposed that ACh-derived choline is transported back into cholinergic nerve terminals and recycled for new ACh synthesis. In this process, choline uptake is mediated through CHT1, which shows high affinity for $\mathrm{HC}-3(\mathrm{Ki}=0.001-0.01 \mu \mathrm{M})$ and choline $(1-5 \mu \mathrm{M})$ (Guyenet et al. 1973; Haga and Noda 1973; Okuda et al. 2012). In most previous superfusion experiments, $10 \mu \mathrm{M} \mathrm{HC}-3$ had been added into perfusion medium to suppress CHT1 activity. HC-3 at this concentration might act on presynaptic mAChRs in addition to inhibiting choline and ACh uptake. On the other hand, lower concentrations (0.1-1 $\mu \mathrm{M})$ of HC-3, which selectively inhibit CHT1 but do not affect ACh uptake, failed to increase $\left[{ }^{3} \mathrm{H}\right]$ efflux evoked by electrical stimulation in superfusion experiments (Muramatsu et al. 2017). These recent results suggest that the increase in $\left[{ }^{3} \mathrm{H}\right]$ efflux by HC-3 is caused by an inhibition of ACh uptake but not choline uptake, implying that ACh-derived choline may not be significantly transported back into cholinergic terminals. Physiological concentrations of choline are relatively high (10-50 $\mu \mathrm{M}$ in plasma and 5-7 $\mu \mathrm{M}$ in cerebrospinal fluid) (Lockman and Allen 2002; Sweet et al. 2001), so that endogenous choline can be continuously supplied from extracellular spaces as a substrate for ACh synthesis. It is interesting to note that perturbations in brain choline homeostasis produce central cholinergic dysfunction (Koppen et al. 1993; Jenden et al. 1990; Sarter and Parikh 2005). These recent results were summarized in this review, and the modified cholinergic transmission mechanisms are proposed in Fig. 3.4.

\subsection{Perspectives}

Cholinergic transmission as well as adrenergic transmission is a prototype of neurotransmission, in which the transmitter is synthesized, stored and released from nerve terminals, and then acts on postsynaptic membrane receptors. Following release, the transmitter undergoes degradation and/or presynaptic reuptake, leading to termination of synaptic transmission. However, recent studies have revealed that the neurotransmission mechanisms may be more complex. In cholinergic transmission in the 


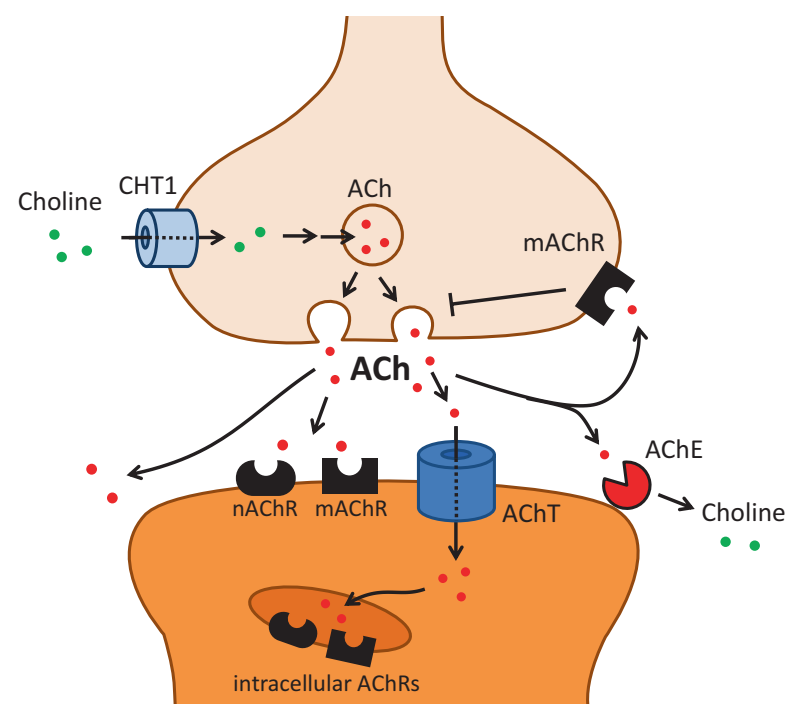

Fig. 3.4 A proposed model of cholinergic transmission in CNS. After release from cholinergic nerve terminals, ACh acts on plasma membrane and intracellular AChRs (mAChRs and/or $\mathrm{nAChRs)}$ in postsynaptic pyramidal neurons, in addition to presynaptic mAChRs. Thus, synaptic ACh concentrations are regulated by AChE hydrolysis, AChT-mediated postsynaptic uptake and presynaptic modulation of release itself. Choline for ACh synthesis may be largely supplied from endogenous choline present at relevant concentrations $(>5 \mu \mathrm{M})$ in the extracellular space, rather than from ACh-degraded choline. Red circles: ACh. Green circles: choline

CNS, released ACh may act both the plasma membrane and intracellular receptors in postsynaptic neurons. ACh itself may be taken up into postsynaptic neurons and act on intracellular receptors. The proposed model (Fig. 3.4) has reopened the issue of classical cholinergic and other neurotransmission mechanisms, and may provide a significant impetus for the pharmacological therapy of neurodegenerative disorders such as Alzheimer's disease.

Acknowledgments We appreciate the kind support of the Life Science Research Laboratory, University of Fukui. This work was supported in part by a Grant-in-Aid for Scientific Research from the Japan Society of the Promotion of Sciences, and a grant from the Smoking Research Foundation of Japan.

Conflict of Interest The authors have no conflicts of interest to declare. 


\section{References}

Akaike A, Tamura Y, Yokota T et al (1994) Nicotine-induced protection of cultured cortical neurons against $\mathrm{N}$-methyl-D-aspartate receptor-mediated glutamate cytotoxicity. Brain Res 644:181-187

Alquicer G, Dolezal V, El-Fakahany EE (2016) Utilization of superfused cerebral slices in probing muscarinic receptor autoregulation of acetylcholine release. In: Myslivecek J, Jakubik J (eds) Muscarinic receptor: from structure to animal models, Neuromethods 107. Humana Press, New York, pp 221-233

Anagnostaras SG, Murphy GG, Hamilton SE et al (2003) Selective cognitive dysfunction in acetylcholine M1 muscarinic receptor mutant mice. Nat Neurosci 6:51-58

Anisuzzaman AMS, Uwada J, Masuoka T et al (2013) Novel contribution of cell surface and intracellular M1-muscarinic acetylcholine receptors to synaptic plasticity in hippocampus. J Neurochem 126:360-371

Apparsundaram S, Ferguson SM, George AL, Blakely RD (2000) Molecular cloning of a human, hemicholinium-3-sensitive choline transporter. Biochem Biophys Res Commun 276:862-867

Benard G, Massa F, Puemte $\mathrm{N}$ et al (2012) Mitochondrial $\mathrm{CB}_{1}$ receptors regulate neuronal energy metabolism. Nat Neurosci 4:558-564

Bliss TV, Collingridge GL (1993) A synaptic model of memory: long-term potentiation in the hippocampus. Nature 361:31-39

Boivin B, Vaniotis G, Allen BG, Hebert TE (2008) G protein-coupled receptors in and on the cell nucleus: a new signaling paradigm? J Recept Signal Transduct Res 28:15-28

den Boon FS, Chameau P, Schaafsma-Zhao Q et al (2012) Excitability of prefrontal cortical pyramidal neurons id modulated y activation of intracellular type-2 cannabinoid receptors. Proc Natl Acad Sci U S A 109:3534-3539

Caccamo A, Oddo S, Billings LM et al (2006) M1 receptors play a central role in modulating AD-like pathology in transgenic mice. Neuron 49:671-682

Caulfield MP, Birdsall NJ (1998) International Union of Pharmacology. XVII. Classification of muscarinic acetylcholine receptors. Pharmacol Rev 50:279-290

Dajas-Bailador F, Wonnacott S (2004) Nicotinic acetylcholine receptors and the regulation of neuronal signaling. Trends Pharmacol Sci 25:317-324

Davi S, Vanhouute P, Pages C et al (2000) The MAPK/ERK cascade targets both Elk-1 and cAMP response element-binding protein to control long-term potentiation-dependent gene expression in the dentate gyrus in vivo. J Neurosci 20:4563-4572

Dineley KT, Pandya AA, Yakel JL (2015) Nicotinic ACh receptors as therapeutic targets in CNS disorders. Trends Pharmacol Sci 36:96-108

Dolezal V, Tucek S (1998) The effects of brucine and alcuronium on the inhibition of [ $\left.{ }^{3} \mathrm{H}\right]$ acetylcholine release from rat striatum by muscarinic receptor agonists. Br J Pharmacol 124:1213-1218

Everitt BJ, Robbins TW (1997) Central cholinergic systems and cognition. Annu Rev Psychol 48:649-648

Fadel JR (2011) Regulation of cortical acetylcholine release: insights from in vivo microdialysis studies. Behav Brain Res 221:527-536

Fernandez de Sevilla D, Nunez A, Borde M et al (2008) Cholinergic-mediated IP3-receptor activation induces long-lasting synaptic enhancement in CA1 pyramidal neurons. J Neurosci 28:1469-1478

Frey U, Frey S, Schollmeier F et al (1996) Influence of actinomycin D, a RNA synthesis inhibitor, on long-term potentiation in rat hippocampal neurons in vivo and in vitro. J Physiol 490(Pt 3):703-711

Gergalova G, Lykhmus O, Komisarenko S et al (2014) $\alpha 7$ nicotinic acetylcholine receptors control cytochrome $\mathrm{c}$ release from isolated mitochondria through kinase-mediated pathways. Int J Biochem Cell Biol 49:26-31 
Giovannini MG (2006) The role of the extracellular signal-regulated kinase pathway in memory encoding. Rev Neurosci 17:619-634

Gold PE (2008) Protein synthesis inhibition and memory: formation vs amnesia. Neurobiol Learn Mem 89:201-211

Guyenet P, Lefresne P, Rossier J et al (1973) Inhibition by hemicholinium- 3 of $\left[{ }^{14} \mathrm{C}\right]$ acetylcholine synthesis and $\left[{ }^{3} \mathrm{H}\right]$ choline high-affinity uptake in rat striatal synaptosomes. Mol Pharmacol 9:630-639

Haga T, Noda H (1973) Choline uptake of rat brain synaptosomes. Biochim Biophys Acta 291:564-575

Huerta PT, Lisman JE (1995) Bidirectional synaptic plasticity induced by a single burst during cholinergic theta oscillation in CA1 in vitro. Neuron 15:1053-1063

Jenden DJ, Rice KM, Roch M et al (1990) Effects of nicotineamide on choline and acetylcholine levels. Adv Neurol 51:131-138

Jong YJ, Kumar V, O’Malley KL (2009) Intracellular metabotropic glutamate receptor 5 (mGluR5) activates signaling cascades activates signaling cascades distinct from cell surface counterparts. J Biol Chem 284:35827-35838

Katz HS, Salehmoghaddam S, Collier B (1973) The accumulation of radioactive acetylcholine by a sympathetic ganglion and by brain: failure to label endogenous stores. J Neurochem 20:569-579

Kihara T, Shimohama S, Sawada $\mathrm{H}$ et al (2001) $\alpha 7$ nicotinic receptor transduces signals to phosphatidylinositol 3-kinase to block a $\beta$-amyloid-induced neurotoxicity. J Boil Chem 276:13541-13546

van Koppen CJ, Kaiser B (2003) Regulation of muscarinic acetylcholine receptor signaling. Pharmacol Ther 98:197-220

Koppen A, Klein J, Huller T et al (1993) Synergistic effect of nicotineamide and choline administration on extracellular choline level in the brain. J Pharmacol Exp Ther 266:720-725

Kruse AC, Kobilka BL, Gautam D et al (2014) Muscarinic acetylcholine receptors: novel opportunities for drug development. Nat Rev Drug Discov 13:549-560

Kuhar MJ, Simon JR (1974) Acetylcholine uptake: lack of association with cholinergic neurons. J Neurochem 22:1135-1137

Langmead CJ, Watson J, Reavill C (2008) Muscarinic acetylcholine receptors as CNS drug targets. Pharmacol Ther 117:232-243

Liang CC, Quastel JH (1969) Effects of drugs on the uptake of acetylcholine in rat brain cortex slices. Biochem Pharmacol 18:1187-1194

Lockman PR, Allen DD (2002) The transport of choline. Drug Dev Ind Pharm 28:749-771

Lykhmus O, Gergalova G, Koval L et al (2014) Mitochondria express several nicotinic acetylcholine receptor subtypes to control various pathways of apoptosis induction. Int J Biochem Cell Biol 53:246-252

Lynch G, Larson J, Kelso S (1983) Intracellular injections of EGTA block induction of hippocampal long-term potentiation. Nature 305:719-721

Ma L, Seager MA, Wittmann M et al (2009) Selective activation of the M1 muscarinic acetylcholine receptor achieved by allosteric potentiation. Proc Natl Acad Sci U S A 106:15950-15955

Mesulam M (2004) The cholinergic lesion of Alzheimer's disease: pivotal factor or side show? Learn Mem 11:43-49

Morishima S, Anisuzzaman ASM, Uwada J et al (2013) Comparison of subcellular distribution and functions between exogenous and endogenous M1 muscarinic acetylcholine receptors. Life Sci 93:17-23

Mrzljak L, Levey AI, Goldman-Rakic P (1993) Association of $\mathrm{m} 1$ and $\mathrm{m} 2$ muscarinic receptor proteins with asymmetric synapses in the primate cerebral cortex: morphological evidence for cholinergic modulation of excitatory neurotransmission. Proc Natl Acad Sci U S A 90:5194-5198

Muramatsu I, Tanaka T, Suzuki F et al (2005) Quantifying receptor properties: the tissue segment binding method - a powerful tool for the pharmacome analysis of native receptors. J Pharmacol Sci 98:331-339 
Muramatsu I, Yoshiki H, Sada K et al (2015) Binding method for detection of muscarinic receptor's natural environment. In: Myslivecek J, Jakubik J (eds) Muscarinic receptor: from structure to animal models, Neuromethods 107. Humana Press, New York, pp 69-81

Muramatsu I, Yoshiki H, Uwada J et al (2016) Pharmacological evidence of specific acetylcholine transport in rat cerebral cortex and other brain regions. J Neurochem 139:566-575

Muramatsu I, Uwada J, Masuoka T et al (2017) Regulation of synaptic acetylcholine concentrations by acetylcholine transport in rat striatal cholinergic transmission. J Neurochem 143:76-86

Nathanson NM (2008) Synthesis, trafficking, and localization of muscarinic acetylcholine receptors. Pharmacol Ther 119:33-43

Nguyen P, Abel T, Kandel ER (1994) Requirement of a critical period of transcription for induction of a late phase of LTP. Science 265:1104-1107

Okuda T, Haga T, Kanai Y et al (2000) Identification and characterization of the high-affinity choline transporter. Nat Neurosci 3:120-125

Okuda T, Osawa C, Yamada H et al (2012) Transmembrane topology and oligomeric structure of the high-affinity choline transporter. J Biol Chem 287:42826-42834

Parsons SM, Prior C, Marshall IG (1993) Acetylcholine transport, storage and release. In: Bradley RJ, Harris RA (eds) International review of neurobiology, vol 35. Academic, New York, pp 279-390

Pittaluga A (2016) Presynaptic release-regulating mGlu1 receptors in central nervous system. Front Pharmacol 7. doi:https://doi.org/10.3389/fphar.2016.00295

Polak RL, Meeuws MM (1996) The influence of atropine on the release and uptake of acetylcholine by the isolated cerebral cortex of the rat. Biochem Pharmacol 15:989-992

Raiteri L, Raiteri M (2000) Synaptosomes still viable after 25 years of superfusion. Neurochem Res 25:1265-1274

Raiteri M, Marchi M, Maura G, Bonanno G (1989) Presynaptic regulation of acetylcholine release in the CNS. Cell Biol Int Res 13:1109-1118

Richardson IW, Szerb JC (1974) The release of labelled acetylcholine and choline from cerebral cortical slices stimulated electrically. Br J Pharmacol 52:499-507

Rosa A, Egea J, Gandia L et al (2006) Neuroprotection by nicotine in hippocampal slices subjected to oxygen-glucose deprivation: involvement of alpha7 nAChR subtype. J Mol Neurosci 30:61-62

Routtenberg A, Rekart JL (2005) Post-translational protein modifications as the substrate for longterm memory. Trends Neurosci 28:12-19

Sarter M, Parikh V (2005) Choline transporters, cholinergic transmission and cognition. Nat Rev Neuosci 6:48-56

Seol GH, Ziburkus J, Huang S et al (2007) Neuromodulators control the polarity of spike-timingdependent synaptic plasticity. Neuron 55:919-929

Shimohama S (2009) Nicotinic receptor-mediated neuroprotection in neurodegenerative disease models. Biol Pharm Bull 32:332-336

Shimohama S, Akaike A, Kimura J (1996) Nicotine-induced protection against glutamate cytotoxicity-nicotinic cholinergic receptor-mediated inhibition of nitric oxide formation. Ann N Y Acad Sci 777:356-361

Shinoe T, Matsui M, Takeko MM et al (2005) Modulation of synaptic plasticity of physiological activation of M1 muscarinic acetylcholine receptors in the mouse hippocampus. J Neurosci 25:11194-11200

Soderling TR, Derkack VA (2000) Postsynaptic protein phosphorylation and LTP. Trends Neurosci 23:75-80

Starke K, Gothert M, Kilbinger H (1989) Modulation of neurotransmitter release by presynaptic autoreceptors. Pharmacol Rev 69:864-989

Sweet DH, Miller DS, Pritchard JB (2001) Ventricular choline transport: a role for organic cation transporter 2 expressed in choroid plexus. J Biol Chem 276:41611-41619

Terry AV, Buccafusco JJ (2003) The cholinergic hypothesis of aged and Alzheimer's diseaserelated cognitive deficits: recent challenges and their implications for novel drug development. J Pharmacol Exp Ther 306:821-827 
Uwada J, Anisuzzaman ASM, Nishimune A et al (2011) Intracellular distribution of functional $\mathrm{M}_{1}$-muscarinic acetylcholine receptors in N1E-115 neuroblastoma cells. J Neurochem 118:958-967

Uwada J, Yoshiki H, Masuoka T et al (2014) Intracellular localization of M1 muscarinic acetylcholine receptor through clathrin-dependent constitutive internalization via a $\mathrm{C}$-terminal tryptophan-based motif. J Cell Sci 127:3131-3140

Volpicelli LA, Levery AI (2004) Muscarinic acetylcholine receptor subtypes in cerebral cortex and hippocampus. Prog Brain Res 145:59-66

Wess J, Eglen RM, Gautam D (2007) Muscarinic acetylcholine receptors: mutant mice provide new insights for drug development. Nat Rev Drug Discov 6:21-733

Williams JH, Kauer JA (1997) Properties of carbachol-induced oscillatory activity in rat hippocampus. J Neurophysiol 78:2631-2640

Wu J, Liu Q, Tang P et al (2016) Heterometric $\alpha 7 \beta 2$ nicotinic acetylcholine receptors in the brain. Trends Pharmacol Sci 37:562-574

Yamasaki M, Matsui M, Watanabe M (2010) Preferential localization of muscarinic M1 receptor on dendritic shaft and spine of cortical pyramidal cells and its anatomical evidence for volume transmission. J Neurosci 30:4408-4418

Zhang W, Basile AS, Gomeza J et al (2002) Characterization of central inhibitory muscarinic autoreceptors by the use of muscarinic acetylcholine receptor knock-out mice. J Neurosci 22:1709-1717

Open Access This chapter is licensed under the terms of the Creative Commons Attribution 4.0 International License (http://creativecommons.org/licenses/by/4.0/), which permits use, sharing, adaptation, distribution and reproduction in any medium or format, as long as you give appropriate credit to the original author(s) and the source, provide a link to the Creative Commons license and indicate if changes were made.

The images or other third party material in this chapter are included in the chapter's Creative Commons license, unless indicated otherwise in a credit line to the material. If material is not included in the chapter's Creative Commons license and your intended use is not permitted by statutory regulation or exceeds the permitted use, you will need to obtain permission directly from the copyright holder.

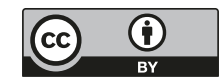

